\title{
Comparison of Psychological Difficulties in Patients with Migraine and Epilepsy Using PARADISE-24 Questionnaire
}

This article was published in the following Dove Press journal: Journal of Multidisciplinary Healthcare

\section{Omid Mirmosayyeb ${ }^{1,2, *}$ Vahid Shaygannejad ${ }^{1,3, *}$ Mahsa Ghajarzadeh ${ }^{2}$}

'Isfahan Neurosciences Research Center, Isfahan University of Medical Sciences, Isfahan, Iran; ${ }^{2}$ Universal Council of Epidemiology (UCE), Universal Scientific Education and Research Network (USERN), Tehran University of Medical Sciences, Tehran, Iran; ${ }^{3}$ Department of Neurology, School of Medicine, Isfahan University of Medical Sciences, Isfahan, Iran

*These authors contributed equally to this work
Correspondence: Mahsa Ghajarzadeh Universal Council of Epidemiology (UCE), Universal Scientific Education and Research Network (USERN), Tehran University of Medical Sciences, Tehran, Iran

$\mathrm{Tel} / \mathrm{Fax}+982166581560$

Emailm.ghajarzadeh@gmail.com
Background: Patients with migraine or epilepsy suffer from a wide range of psychological difficulties, and various instruments are needed to separately assess each difficulty. However, the PARADISE-24 questionnaire is a comprehensive questionnaire for evaluating different psychological difficulties in cases with neurological disorders.

Objective: The aim of this study was to compare psychological difficulties in patients with migraine and those with epilepsy by using the PARADISE-24 questionnaire.

Methods: Overall, 240 migraineurs and 210 patients with epilepsy were enrolled. All the participants were asked to fill the Persian version of the PARADISE-24 questionnaire.

Results: In migraineurs, the mean age and mean headache severity (by means of visual analogue scale, VAS) were $38.6 \pm 11.6$ and $6.8 \pm 2.8$, respectively. In patients with epilepsy, the mean age and mean duration of the disease were $33.6 \pm 13.4$ and $12 \pm 10.3$ years, respectively. The mean PARADISE score was significantly higher in migraineurs than in epileptic cases $(57.9 \pm 12$ vs $50.7 \pm 15.1)(\mathrm{p}<0.001)$.

Conclusion: Patients with migraine suffer more from psychological difficulties than epileptic cases. This finding could help physicians to pay more attention to psychological wellbeing.

Keywords: migraine, epilepsy, psychological, Iran

\section{Introduction}

Migraine is a devastating condition characterized by severe headache, and in some cases, accompanied by an aura. ${ }^{1}$ With the prevalence rate from $10 \%$ to $18 \%$, it affects women more than men, yet the exact etiology is still unknown. ${ }^{2-4}$ It is the second cause of "years lost due to disability" (YLDs), imposing considerable costs to both patients and the health system. ${ }^{5}$

The other chronic condition is epilepsy that is characterized by unprovoked seizures, affecting all age groups (neonates to elderlies). ${ }^{6}$ Along with neurological disabilities, epilepsy causes psychological and psychiatric complications, affecting different aspects of life. ${ }^{7,8}$ People with epilepsy have a higher rate of mortality and a lower quality of life. ${ }^{9-11}$

Migraine and epilepsy are both among prevalent disabling conditions in all countries, including Iran. It is important to assess the impact of brain disorders on the patient's life to help physicians better determine treatment outcomes and monitor the disease course, although there is no exact method to be used for this purpose. Some studies found a common pattern of psychosocial difficulties among 
patients with neurological disorders, so PARADISE-24 (Psychosocial fActors Relevant to BrAin DISorders in Europe) was developed by Cieza et al. ${ }^{12}$

We designed this study to compare psychological difficulties in patients with migraine and those with epilepsy, using PARADISE-24 questionnaire.

\section{Methods}

This cross-sectional study was conducted in Isfahan Neurosciences Research Center (INRC), Kashani hospital, between January and April 2020.

1. Inclusion criteria for migraineurs were (a) headache history of more than two years, (b) diagnosis of migraine according to IHS ICHD-3 criteria, (c) patients under surveillance by a physician for headache treatment, (d) use of medications for ${ }^{3} 16$ weeks, and (e)

2. 18 years of age and above.

Exclusion criteria for migraine group were:

- evidence of a secondary headache disorder attributed to

- head and/or neck trauma,

- cranial or cervical vascular disorder, or a $n$

- on-vascular cranial disorder,

- substance use or withdrawal,

- infection,

- hemostasis disorder,

- psychiatric disorder,

- current major medical illness such as malignancy,

- autoimmune or immune deficiency, diabetes mellitus, or $\mathrm{u}$

- uncontrolled psychosis and pregnancy.

Inclusion criteria for epileptic cases were (a) diagnosis of epilepsy according to the International League Against Epilepsy (ILAE) Classification of the Epilepsies (2017) (b) 20 years of age or above; (c) two or more verified unprovoked epileptic seizures with at least 24-h time gap; and (d) at least one seizure within the previous 5 years.

Exclusion criteria for epileptic cases were:

1. head and/or neck trauma

2. migraine or other types of headache

3. non-vascular cranial disorder

4. substance use or withdrawal
5. infection

6. disorder of hemostasis

7. psychiatric disorder

8. current major medical illness such as malignancy, a

9. autoimmune or immune deficiency, diabetes mellitus, or

10. uncontrolled psychosis

11. and pregnancy

All patients were asked to fill the informed consent forms before entering the study. The study was approved by the ethics committee of Isfahan university of medical sciences and that it was conducted in accordance with the Declaration of Helsinki.

The two patient groups were consecutively enrolled in the study, and the researcher was not blinded to the disease.

The PARADISE-24 is a self-report questionnaire, with questions answered on a 3 -point scale (none $=0$, some $=1$, a lot $=2$ ). The total score ranges from 0 to 100 , while higher scores indicate psychosocial difficulties due to brain disorders. ${ }^{12}$

All participants were asked to fill a valid and reliable Persian version of the PARADISE-24 questionnaire. ${ }^{13}$

Data regarding age, sex, educational level, number of days per week with headache, frequency of headache per day, and severity of headache (using a visual analogue scale) were recorded for migraineurs cases. For epileptic cases, age, sex, educational level, duration of the disease, disease status (under control or not), and frequency of seizures per day were considered. Seizure-free was defined as having no attack for at least 1 year.

We used SPSS software version 22 (SPSS Inc., Chicago, IL, USA) to do data analysis. Data were presented as mean \pm SD for continuous and as frequencies for categorical variables. Independent sample $t$-test and Fisher exact test were used for comparison between quantitative and qualitative variables. A p-value of less than 0.05 was considered significant.

\section{Results}

The data were gathered from 240 migraineurs and 210 patients with epilepsy enrolled in this study. In migraineurs, mean age and mean headache severity were 38.6 \pm 11.6 and $6.8 \pm 2.8$, respectively. The mean PARADISE score was $57.9 \pm 12$ (Table 1).

\section{Discussion}

The current study showed a significantly higher mean PARADISE score for migraineurs than patients with 
Table I Characteristics of Migraineurs

\begin{tabular}{|l|l|}
\hline Characteristics & Values \\
\hline Age (year), mean $\pm \mathrm{sd}$ & $38.6 \pm \mathrm{II} .6$ \\
\hline $\begin{array}{l}\text { Sex, } \mathrm{n} \\
\text { Male }\end{array}$ & 46 \\
Female & 194 \\
\hline $\begin{array}{l}\text { Education level (year), mean } \pm \mathrm{sd} \\
\text { Severity of the headache, mean } \pm \text { sd }\end{array}$ & $12.2 \pm 4.4$ \\
\hline $\begin{array}{l}\text { Number of the days with headache in a week, } \mathrm{n}(\%) \\
\text { I-2 }\end{array}$ & $6.8 \pm 2.8$ \\
\hline $\begin{array}{l}\text { 5-4 } 6 \\
7\end{array}$ & $49(10.9)$ \\
During a month & $57(12.7)$ \\
\hline Total PARADISE-24 score, mean \pm sd & $36(8)$ \\
\hline
\end{tabular}

Notes: There was no significant difference between migraineurs regarding sex and the number of days with headache. In patients with epilepsy, the mean age and mean duration of the disease were $33.6 \pm 13.4$ and $12 \pm 10.3$ years, respectively. The mean PARADISE score was $50.7 \pm 15.1$ (Table 2).

epilepsy, which indicates that patients with migraine suffer more from psychosocial difficulties than the other group.

In a previous study conducted by Raggi et al the mean PARADISE score in patients with migraine was reported as $59.9 \pm 7.6$, which is higher than our score. Yet congruent

Table 2 Characteristics of the Patients with Epilepsy

\begin{tabular}{|c|c|}
\hline Characteristics & Values \\
\hline Age (year), mean \pm sd & $33.6 \pm 13.4$ \\
\hline Duration of the disease (year), mean \pm sd & $12 \pm 10.3$ \\
\hline \multicolumn{2}{|l|}{ Type of epilepsy, n (\%) } \\
\hline GTC & $80(39.2)$ \\
\hline Focal & $99(48.5)$ \\
\hline Myoclonic & $31(15.1)$ \\
\hline \multicolumn{2}{|l|}{ Sex, n (\%) } \\
\hline Male & $79(37.6)$ \\
\hline Female & $|3|(62.4)$ \\
\hline \multicolumn{2}{|l|}{ Seizure/epilepsy free, n (\%) } \\
\hline Yes & $126(60)$ \\
\hline No & $84(40)$ \\
\hline Total PARADISE-24, mean \pm sd & $50.7 \pm 15.1$ \\
\hline
\end{tabular}

Notes: The mean score was significantly different between patients whose seizures were under control and those were not $(49.8 \pm 15.9$ vs $65.4 \pm 9.1, p<0.001)$. There was no significant difference between patients regarding sex and the type of epilepsy. The mean PARADISE score was significantly higher for migraineurs than epileptic cases $(57.9 \pm 12$ vs $50.7 \pm \mid 5.1)(p<0.001)$.

Abbreviation: GTC, generalized tonic-clonic. with our findings, they reported no significant difference between male and female patients. ${ }^{14}$

Patients with migraine suffer from a wide range of psychological difficulties such as depression, poor sleep, sexual dysfunction, anxiety, and impaired quality of life, ${ }^{15,16}$ each of which requires a specific questionnaire or instrument to be assessed. One of the advantages of the PARADISE questionnaire is assessing various psychological aspects such as anxiety and depression, pain, sensory disturbances, and sleep difficulties. ${ }^{14}$

Migraine is a chronic disabling neurological disease, causing near 45 million years lived with disability (YLDs), and is the second disabling condition after low back pain. ${ }^{17}$ It affects occupational, social, economic, and personal aspects of life, and its consecutive complications, including psychological problems, impair the quality of life. ${ }^{18}$ The quality of life in migraineurs is inversely correlated with days with headache and headache-associated disabilities. ${ }^{19}$ Furthermore, many health conditions are considered to be associated with migraine, such as cardiovascular disease, epilepsy, multiple sclerosis, restless legs syndrome, fibromyalgia, asthma, allergic rhinitis, and systemic lupus erythematosus. ${ }^{18}$ These physical disorders, along with psychological problems, make migraine as one of the most devastating conditions that should be carefully monitored by physicians.

Epilepsy is another neurological disorder associated with lower quality of life and psychological problems such as sexual dysfunction, depression, anxiety, memory dysfunction, and stigma. ${ }^{20,21}$ To evaluate these complications, different instruments should be used, while the PARADISE-24 questionnaire provides a comprehensive assessment tool.

The mean PARADISE score in our patients with epilepsy was $50.7 \pm 15.1$. According to Quintas et al study on 80 cases with epilepsy, the mean PARADISE score was $50.9 \pm 8.9$, and the quality of life score was negatively related to the PARADISE score. ${ }^{22}$

Different somatic disorders have been considered to be associated with epilepsy, such as tumors, diabetes mellitus, migraine, chronic obstructive pulmonary disease (COPD), peptic ulcers, cardiovascular diseases, and cataract. ${ }^{23}$

Among neurological disorders, epilepsy accounts for the highest age-standardized DALY (the disability-adjusted life year) in both sexes, which is $0.7 \%$ of total DALYs. ${ }^{24}$

Epilepsy affects education, occupation, familial relations, and childbearing, which affects health-related quality of life. ${ }^{25}$ So, monitoring and careful evaluation of the 
patients play an important role in somatic and psychological well-being.

This study showed that patients with migraine suffer more from psychological problems than epileptic cases. This finding could guide the physicians to consider psychological well-being in migraineurs (clinical meaningfulness). However, it had some limitations: First, it was conducted in a single center. Second, we did not apply the quality of life instruments. Multi-centric studies with an evaluation of other aspects of the disease are recommended.

\section{Conclusion}

Patients with migraine suffer more from psychological difficulties than epileptic cases. This finding could help physicians to pay more attention to psychological well-being.

\section{Disclosure}

The authors report no conflicts of interest in this work.

\section{References}

1. Jalilian R, Ghajarzadeh M, Fateh R, Togha M, Sahraian MA, Azimi A. Comparison of sleep quality in women with migraine moreover, multiple sclerosis. Acta Med Iran. 2014;690-693.

2. Stovner LJ, Zwart JA, Hagen K, Terwindt G, Pascual J. Epidemiology of headache in Europe. Eur J Neurol. 2006;13(4):333-345. doi:10.1111/j.1468-1331.2006.01184.x

3. Woldeamanuel YW, Cowan RP. Migraine affects 1 in 10 people worldwide featuring recent rise: a systematic review and meta-analysis of community-based studies involving 6 million participants. J Neurol Sci. 2017;372:307-315. doi:10.1016/j.jns.2016.11.071

4. Buse DC, Rains JC, Pavlovic JM, et al. Sleep disorders among people with migraine: results from the chronic migraine epidemiology and outcomes (CaMEO) study. Headache. 2019;59(1):32-45. doi:10.1111/ head. 13435

5. Vos T, Abajobir AA, Abate KH. Global, regional, and national incidence, prevalence, and years lived with disability for 328 diseases and injuries for 195 countries, 1990-2016: a systematic analysis for the Global Burden of Disease Study 2016. Lancet (London, England). 2017;390(10100):1211-1259. doi:10.1016/S0140-6736(17)32154-2

6. Song P, Liu Y, Yu X, et al. Prevalence of epilepsy in China between 1990 and 2015: a systematic review and meta-analysis. J Glob Health. 2017;7(2):020706. doi:10.7189/jogh.07.020706

7. Tellez-Zenteno JF, Patten SB, Jetté N, Williams J, Wiebe S. Psychiatric comorbidity in epilepsy: a population-based analysis. Epilepsia. 2007;48(12):2336-2344. doi:10.1111/j.1528-1167.2007.01 222.x

8. Hermann B, Seidenberg M, Jones J. The neurobehavioural comorbidities of epilepsy: can a natural history be developed? Lancet Neurol. 2008;7(2):151-160. doi:10.1016/S1474-4422(08)70018-8
9. Thurman DJ, Beghi E, Begley CE, et al. Standards for epidemiologic studies and surveillance of epilepsy. Epilepsia. 2011;52:2-26. doi:10.1111/j.1528-1167.2011.03121.x

10. Ngugi AK, Bottomley C, Kleinschmidt I, Sander JW, Newton CR. Estimation of the burden of active and life-time epilepsy: a metaanalytic approach. Epilepsia. 2010;51(5):883-890. doi:10.1111/ j.1528-1167.2009.02481.x

11. Baker GA, Jacoby A, Buck D, Stalgis C, Monnet D. Quality of life of people with epilepsy: a European study. Epilepsia. 1997;38 (3):353-362. doi:10.1111/j.1528-1157.1997.tb01128.x

12. Cieza A, Sabariego C, Anczewska M, et al. PARADISE 24: a measure to assess the impact of brain disorders on people's lives. PLoS One. 2015;10(7):7. doi:10.1371/journal.pone.0132410

13. Azimi ADR, Mohammad Vali Samani S, Roostaei B, Hamtaei Gashti S, Navardi S, Ghajarzadeh M.Psychometric properties of the Persian version of the PARADISE-24 questionnaire, Running title: Persian version of the PARADISE-24 questionnaire. IJPM.2020 IP.

14. Raggi A, Covelli V, Schiavolin S, et al. Psychosocial difficulties in patients with episodic migraine: a cross-sectional study. Neurol Sci. 2016;37(12):1979-1986. doi:10.1007/s10072-016-2705-8

15. Lantéri-Minet M, Radat F, Chautard M-H, Lucas C. Anxiety and depression associated with migraine: influence on migraine subjects' disability and quality of life, and acute migraine management. Pain. 2005;118(3):319-326. doi:10.1016/j.pain.2005.09.010

16. Ghajarzadeh M, Jalilian R, Togha M, Azimi A, Hosseini P, Babaei N. Depression, poor sleep, and sexual dysfunction in migraineurs women. Int J Prev Med. 2014;5(9):1113.

17. Stovner LJ, Nichols E, Steiner TJ, et al. Global, regional, and national burden of migraine and tension-type headache, 1990-2016: a systematic analysis for the Global Burden of Disease Study 2016. Lancet Neurol. 2018;17(11):954-976. doi:10.1016/S1474-4422(18) 30322-3

18. Burch RC, Buse DC, Lipton RB. Migraine: epidemiology, Burden, and Comorbidity. Neurol Clin. 2019;37(4):631-649. doi:10.1016/j. ncl.2019.06.001

19. Abu Bakar N, Tanprawate S, Lambru G, Torkamani M, Jahanshahi M, Matharu M. Quality of life in primary headache disorders: a review. Cephalalgia. 2016;36(1):67-91. doi:10.1177/ 0333102415580099

20. Quintas R, Raggi A, Giovannetti AM, et al. Psychosocial difficulties in people with epilepsy: a systematic review of literature from 2005 until 2010. Epilepsy Behav. 2012;25(1):60-67. doi:10.1016/j. yebeh.2012.05.016

21. Morrell MJ. Sexual dysfunction in epilepsy. Epilepsia. 1991;32(s6): S38-S45. doi:10.1111/j.1528-1157.1991.tb05891.x

22. Quintas R, Cerniauskaite M, Giovannetti AM, et al. PARADISE 24 instrument: an observational study on psychosocial difficulties, quality of life, and disability levels in patients with epilepsy. Epilepsy Behav. 2016;64:160-165. doi:10.1016/j.yebeh.2016.08.019

23. Beghi E. Addressing the burden of epilepsy: many unmet needs. Pharmacol Res. 2016;107:79-84. doi:10.1016/j.phrs.2016.03.003

24. Whiteford HA, Ferrari AJ, Degenhardt L, Feigin V, Vos T. Global burden of mental, neurological, and substance use disorders: an analysis from the Global Burden of Disease Study 2010. Mental Neurol Subst Use Disord. 2015;29.

25. Cianchetti C, Messina P, Pupillo E, et al. The perceived burden of epilepsy: impact on the quality of life of children and adolescents and their families. Seizure. 2015;24:93-101. doi:10.1016/j.seizure.20 14.09.003 


\section{Publish your work in this journal}

The Journal of Multidisciplinary Healthcare is an international, peerreviewed open-access journal that aims to represent and publish research in healthcare areas delivered by practitioners of different disciplines. This includes studies and reviews conducted by multidisciplinary teams as well as research which evaluates the results or conduct of such teams or healthcare processes in general. The journal covers a very wide range of areas and welcomes submissions from practitioners at all levels, from all over the world. The manuscript management system is completely online and includes a very quick and fair peer-review system. Visit http://www.dovepress.com/testimonials. php to read real quotes from published authors.

Submit your manuscript here: https://www.dovepress.com/journal-of-inflammation-research-journal 